\title{
“EL PRESENTE ERA UN PESO Y UN ESTORBO”. SUBJETIVIDADES DE LA HUERFANÍA EN LA NARRATIVA DEL COLOMBIANO JUAN GABRIEL VÁSQUEZ*
}

\author{
Daniuska González González \\ Centro de Estudios Avanzados (CEA)/Facultad de Humanidades, \\ Universidad de Playa Ancha, Valparaíso, Chile \\ daniuska.gonzalez@upla.cl
}

\section{RESUMEN / ABSTRACT}

Partiendo de la premisa de que la propuesta del novelista colombiano Juan Gabriel Vásquez (Bogotá, 1973) se deslinda de la narrativa explícita de la violencia, sobre todo de la denominada "narcoliteratura", y recurriendo en la metodología a autores teóricos como Jameson, Bauman, Vattimo, Chambers y Thiebaut, en el presente artículo analizaré la construcción de la noción de sujeto en las novelas El ruido de las cosas al caer (2011), Las reputaciones (2013) y La forma de las ruinas (2015) a partir de la condición de huerfanía, un registro que se deslinda de un estado que tiene que ver con el pasado y con la orfandad por la infancia, para instalarse en el presente y el futuro y definirlo a partir del hastío y la anomia.

Palabras CLAVE: Juan Gabriel Vásquez, literatura hispanoamericana, crítica literaria, siglo XXI.

\section{“THE PRESENT WAS A WEIGHT AND AN OBSTACLE" SUBJECTIVITIES OF ORPHANAGE IN THE NARRATIVE OF THE COLOMBIAN JUAN GABRIEL VÁSQUEZ}

This article begins with the premise that the literature of Colombian novelist Juan Gabriel Vásquez (Bogotá, 1973) differs significantly from explicit narratives of violence, especially in so-called "narcoliterature." In dialogue with ideas from authors such as Jameson, Bauman, Vattimo, Chambers and Thiebaut, it examines the construction of the subject in Vásquez's novels El ruido de las cosas al caer (2011), Las reputaciones (2013), and La forma de las ruinas (2015). In particular, it understands this construction of the subject in relation to the Chilean poet Jaime Quezada>s term "huerfania" ("orphanhood"), a condition that arises from childhood feelings and fills the subject's present life with boredom and anomie.

Agradezco a la colega Raquel Rivas Rojas por nuestro diálogo en torno a este artículo. 
KEYWORDS: Juan Gabriel Vásquez; HispanoamericanLiterature;LiteraryCriticism; XXI century.

"te mirabas en el espejo y te veías el alma. Te descubrías. [...] Todos descubríamos o, revelábamos impotentes, quiénes éramos. Quién era realmente uno. Ésa era la zona de interés". Martin Amis, La zona de interés

\section{INTRODUCTORIO: LAS “CARAS AUSENTES” DE LA HUERFANÍA}

Un sujeto que comparte rasgos constitutivos similares se construye en las tres últimas novelas de Juan Gabriel Vásquez. En El ruido de las cosas al caer (2011, Premio Alfaguara de Novela de ese año) el sujeto ${ }^{1}$ Antonio Yammara ostenta una voz apolítica y desganada frente a su mundo, un mundo dejado en la inermidad por la narcoguerra de los carteles y con paisajes rotos emocional y geográficamente; en Las reputaciones (2013) el reconocido caricaturista Javier Mallarino recibe un prestigioso premio y a partir de éste se desencadenan acontecimientos que lo harán dudar de sus actuaciones y que echarán por tierra hasta sus más íntimos convencimientos, mientras que en La forma de las ruinas (2015) los sujetos se hallan a la intemperie histórica del pasado y del presente, sin asideros adonde recurrir con vista al futuro; como la historia nacional, ellos también han ido armándose a través de las ruinas.

La narrativa de Vázquez se separa de escrituras como las de Fernando Vallejo, Jorge Franco, Mario Mendoza o Gustavo Bolívar, por citar solo a cuatro autores colombianos de reciente referencia obligada. Ya no se trata de punzar el cuerpo de la violencia y de hacer un paneo sobre los victimarios

1 Entendiendo la categoría sujeto a partir de las nociones de Michel Foucault sobre todo en La hermenéutica del sujeto y Tecnologías del yo y otros textos afines, acerca de la inmanencia de una subjetivación, es decir, la práctica de la gubernamentalidad, rasgo constitutivo de la época postmoderna, produce una identidad particular de sujeto la cual se constituye en "la intersección entre los actos que han de ser regulados y las reglas sobre lo que ha de hacerse" (Tecnologías del yo y otros textos afines 72). Sujeto "no en el sentido de una sujeción sino de una subjetivación" (La hermenéutica del sujeto 483) y cuyo propósito se encamina al conocimiento de sí mismo; sus actos están en función de una búsqueda del conocimiento personal, originándose una "puesta en juego del sujeto por sí mismo en la inquietud que tiene de sí" (494). 
con aquella exuberante Rosario Tijeras o los sicarios como Wilmar o Jairo implorando la protección divina que solo les otorga la muerte cual objetos desechables que son; o rastrear la conformación de una sociedad arrasada por atentados, secuestros y asesinatos. A lo que aspira un autor como Vásquez es a tematizar a un sujeto huérfano, caído en la apatía y la desesperanza pero tan letal como los carros-bomba que estallaban en la "narcoliteratura".

La propuesta de este artículo ${ }^{2}$ problematizará el concepto de huerfanía ${ }^{3}$, traído desde la literatura ${ }^{4}$, para entender el proceso de movilidad del sujeto contemporáneo en las novelas de Vásquez. De esta manera interesa darle una vuelta de tuerca a este término y separarlo de la orfandad, para deslastrarlo de

2 Sobre el estado de la cuestión se señala que no obstante la prolífica producción literaria de Vásquez, que incluye siete novelas (Persona, 1997; Alina suplicante, 1999; Los informantes, 2004; Historia secreta de Costaguana, 2007; El ruido de las cosas al caer, 2011; Las reputaciones, 2013; y La forma de las ruinas, 2015), un libro de cuentos (Los amantes de Todos los Santos, 2001), una biografía (Joseph Conrad: el hombre de ninguna parte, 2004) y dos volúmenes de ensayos (El arte de la distorsión, 2009 y Viajes con un mapa en blanco, 2017), los textos académicos sobre su obra son escasos y guardan poca relación con el presente artículo, entre éstos se destacan: "Del lugar de paso al lugar para el olvido: Bibliowicz, Schwartz, Vásquez" (2008) de Luz Mary Giraldo; "Espejos, simulacros y distorsiones: Hacia una tipología de la 'metaficción historiográfica' en Historia secreta de Costaguana, de Juan Gabriel Vásquez" (2010) de Ricardo Carpio; "Una mirada en los abismos de la historia. La impronta de Pynchon, Borges y Sebald sobre Los informantes de Juan Gabriel Vásquez" (2012) de Jasper Vervaeke, "La razón de ser de la presencia de Joseph Conrad en El sueño del celta de Mario Vargas Llosa e Historia secreta de Costaguana de Juan Gabriel Vásquez" (2015) y "Una geografía de la memoria en Los informantes de Juan Gabriel Vásquez y El mundo de afuera de Jorge Franco" (2016), ambos de Caroline Houde, e "Intermedialidad y archivo en la literatura de crimen" (2016) de Angélica Tornero. Llama la atención tratándose además de un reconocido articulista en medios de comunicación importantes de Colombia y del extranjero, como El País.

La orfandad remite, sobre todo, a la infancia como un vínculo que establece una memorabilia de pérdidas y, en algunos casos, traumas, instalando la categoría de sujetos huérfanos, "aquéllos que no logran sustento en el árbol genealógico; sujetos que para pararse en sus dos pies, deben consumir la biografía de otros (especialmente del padre o sus sustitutos). La voz propia surge de la predicación de una voz próxima a la cual se está adherida. Sujetos placentarios, que se remiten al origen para dar el corte final que les permita constituirse como personas de libre albedrío" (Cánovas 125).

$4 \quad$ Esto a riesgo de parecer una tautología; sin embargo, la condición de huerfanía como asidero para comprender el presente y la infertilidad de posibilidades futuras llamó la atención de la investigadora desde el primer acercamiento al poemario como parte de un entendimiento mayor acerca de "La individualidad contemporánea [que] experimenta procesos de crisis y cuestionamientos" (Güelman y Borda 1). 
esta sujeción a la infancia e instalarlo dentro de la carencia y el extrañamiento del tedio postmoderno, indicador, como observó Jean-François Lyotard, de "un estado de ánimo o mejor, de pensamiento [...] de un cambio de relación con el problema del sentido" (“¿Qué es lo Postmoderno?” 1); es decir, acercarse a cómo estos sujetos operan dentro del discurso del desafecto presente y por venir en la sociedad contemporánea.

En una aproximación al poemario Huerfanía del chileno Jaime Quezada (Los Ángeles, Chile, 1942) puede leerse que a través de la huerfanía "[se] pone de manifiesto una visión apocalíptica de la existencia humana, expresada mediante el uso de motivos e imágenes literarias que aluden a la orfandad, el desamparo" (S/A 1). Esta cita se enfatiza, la única sobre esta palabra en el sentido que interesa, para acoplarla a la sensación de carencia, extrañamiento y ofuscación inherentes al presente del sujeto postmoderno, que nada espera del futuro porque ha llegado hasta aquí sin esperanza y ve el diario devenir como un conjunto de trozos desparramados, incoherentes y tocados en algún momento por la violencia y la ajenidad de un entorno donde no logra integrarse. El poeta Quezada aclara: "Huerfanía [...] Es una vuelta [...] a una noche oscura, a un pretérito de tinieblas y, a su vez, a un tiempo por-porvenir en sus visiones apocalípticas" ("Mi poética" 119); la voz poética sobrepone pasado con futuro y el presente queda como un intermedio sin anclaje, como un espaciado sin contorno nítido.

\section{CIUDADANÍAS HUÉRFANAS: ACOTACIONES TEÓRICAS NECESARIAS}

La idea de la huerfanía se vincula con la incompletud y el deslave de certezas, desde esta condición se constituyen los sujetos de Vásquez que, aunque exhiben "formas reflexivas de autoentendimiento" (Thiebaut, "La construcción" 203) como corresponde a la categoría de sujeto, muestran una incapacidad crítica ${ }^{5}$ para interrogarse profundamente por el presente.

Un breve poema en prosa titulado "Cada cual con su quimera" permite observar a Charles Baudelaire deteniéndose en el hombre moderno, un hombre

\footnotetext{
Aunque el final de Las reputaciones subraya la toma de decisión más importante en la vida de Mallarino, el texto está atravesado por la dubitación del sujeto y por su distanciamiento de la sociedad a la que alude como extraña.
} 
"encorvado" (Pequeños poemas 25) y de "rostro agotado y serio" (26), atrapado entre la realidad difícil, "con la faz resignada de los condenados a esperar siempre" (26) y los sueños futuros carentes de esperanza, metaforizados en las quimeras que carga sobre sus hombros y las cuales resultan "tan pesada[s] como un saco de harina o de carbón" (25). Para el poeta el futuro se agolpa con tanta dureza como el presente de trabajo explotador.

A partir de esta imagen se analizará la huerfanía como una sensación de anomia que corroe el presente y la posibilidad de un mañana de resarcimiento (aunque sea utópico) en el sujeto. El presente lo hace tan huérfano como el pasado que ha transcurrido. Después del paso de esta caravana de individuos como sombras, Baudelaire confesó que quedó "hondamente agobiado" (Pequeños poemas 26). Con idéntica sensación el sujeto contemporáneo se mira a sí mismo y a los otros, su mundo gira en torno al desencanto, un desencanto constituido por "la pérdida de una ilusión y, por lo mismo, una resignificación de la realidad" (Lechner 13), ya que "No conoce mediación entre el presente y un futuro radicalmente otro" (32). Solo entre la muchedumbre, también tan solitaria como él, paradójicamente, sitúa su condición de ajenidad y desencanto. A este sujeto el desapego lo arropa.

En algún punto, el pasado lo ha convertido en huérfano y lo ha dejado sin paisajes y palabras adonde asirse, lo cual no extraña. Sin embargo sí ocasiona asombro cuando a su presente lo reemplaza con idénticas carencias y lo empuja hacia la más absoluta deriva: ahora a la pérdida de las coordenadas pasadas se le añaden las actuales como imposibilidad para sostenerse. El sujeto está en constante reconstrucción hacia el pasado como hacia el presente y el futuro, por esta razón, como definió Leonor Arfuch, es un laboratorio móvil de identidad (98), de ahí su inestabilidad y su continua desfragmentación. En esta dirección lo que se propone es asentar que el tiempo de la subjetividad se produce a través de la huerfanía, que ella invoca y también convoca para que "nada [en la vida del sujeto] est[é] en su lugar" (Lechner 14), al contrario, que se desarme y quede expuesta.

Parafraseando a Gianni Vattimo en su aproximación a Nietzsche ([1974]1989), se trataría en la narrativa de Vásquez de un sujeto con "una percepción [...] del carácter efímero, relativo, insignificante de toda acción y decisión, como para resultarle imposible actuar aún verdaderamente en la historia" (25). Huérfano, este sujeto no anda libre de sentimientos, emociones o apegos a lugares y a personas sino que esto no se traduce en compromiso, como una metáfora del ave que planea sobre disímiles paisajes pero sin posarse. 
Así se mezcla la materia constitutiva entre el sujeto contemporáneo y la huerfanía, esta última no como rémora del pasado, no obstante conformar éste el estado del presente, "Ser huérfano es eso: no hay nadie por delante, [...]. Es dura, la mirada de los ausentes" (Vásquez, El ruido 109) sino como requisito para tamizar el ahora. Sujeto a la intemperie en la vida cotidiana y en los afectos; en la superficie y en su interioridad; en el mundo de tensiones y retenciones que han construido las últimas modernidades, no en balde "líquidas" como las adjetivó Bauman, porque todo se desparrama o se llena sin soporte y sin validación ni fe.

El sentimiento de dislocamiento y apatía de estos seres huérfanos del ayer y del hoy produce desasosiego, el mismo agobio baudeleriano, y cualquier gesto de afecto parece tragado por el desgano. Sujetos que cargan el pasado como una quimera pero la huerfanía la determina el presente y las pocas luces hacia el futuro.

En ese texto imprescindible para entender las dinámicas de la globalización, Migración, Cultura, Identidad, Chambers acota que el "sujeto [...] pierde su certeza cartesiana y sólo puede reconocerse a sí mismo cuando está `en juego', en movimiento" (161). En diálogo con el concepto de huerfanía, ésta construye una gestualidad del desconcierto y de la movilidad sensorial, anímica e intelectual; como sintetizó Quezada "[en ella] andan los desgarramientos del ser humano [...]. Un testimoni[o] [de] mis orfandades, mis contingencias y mis significaciones" ("Mi poética" 121), sobre todo las del presente azaroso. Con Chambers se continúa para razonar que "Hacer visible el gesto es privilegiar el fragmento, el acontecimiento, el cuerpo, la voz" (171), en el caso particular de los sujetos de Vásquez desde la confusión y el desaliento. Como, por ejemplo, la ciudad que Mallarino y el escritor Vásquez cruzan, ciudad otra, "ciudad desaparecida, [...] ciudad fantasma" (Las reputaciones 21); o el lugar de la infancia reproducido por Yammara desde la ruina: "era eso, nuestro pasado común, lo que estaba allí sin estar, como el óxido que no se veía pero que carcomía" (El ruido 236): todo atestigua gestos de una falta presente, vívida, que produce identidades que "habit[an] en un espacio, en un cuerpo y lenguaje específicos y en los hilos conductores de historias que los entretejen en este lugar" (Chambers 164-165), posibilitando comprender, con el poeta Quezada, que la huerfanía es un tiempo presente de destierro interior. 


\section{YAMMARA: UN SUJETO EN LA ZONA DE INTERÉS ${ }^{6}$}

El sujeto de esta novela acumula más que las heridas físicas del atentado que sufrió, es la metáfora del huérfano de una guerra donde no participó y que paradójicamente lo arrastró hasta convertirlo en un transeúnte emocional en la sociedad. A Yammara lo impacta tardíamente la época de violencia de Pablo Escobar, pues los sicarios que le hieren y asesinan a su acompañante Ricargo Laverde luego de cumplir su condena por tráfico de droga aparecen veinte años después, en un ajuste de cuentas que cose el final de una historia de encrucijadas vitales y horror.

Hasta el momento cuando le disparan iba a la deriva, sin mirar el presente que lo condiciona, ese "presente [que para él] no existe en realidad: todo es recuerdo, esta frase que acabo de escribir ya es recuerdo" (Vásquez, El ruido 23), ni el futuro que encierra en una pregunta a Maya, la hija de Laverde: “¿Qué [se] ve?” (251). A Yammara lo atraviesa la memoria como el tener lugar (Benjamin), como el vínculo entre los objetos y su lugar de ocupación en el pasado, pero que se forja en la incompletud; sus escasos recuerdos adquieren el estatus de fragmentos, de pedazos en fuga, como cuando visita la Hacienda Nápoles y asiente ante la afirmación de Maya: “Todo parece más pequeño'. [...] no fue nuestra decepción lo que nos sorprendió, sino la manera en que la vivimos juntos" (Vásquez, El ruido 234).

Sujeto que sobrevive a la huerfanía del ahora. Apático, semeja un devenir idéntico al dejarse ir baudeleriano, ajeno a las multitudes las que solo disfrutarán aquellos con "gusto del disfraz y la careta, el odio del domicilio y la pasión del viaje" (Baudelaire, Pequeños poemas 35); y cansa verlo en "esa rutina que gira alrededor de la cátedra [...] los salones sin voces, las oficinas sin ajetreos" (Vásquez, El ruido 34), en "los billares de la calle 14, lugares llenos de humo y de techos bajos donde ocurría la otra vida, la vida sin doctrinas ni jurisprudencias" (17) donde parece flotar o detentar una condición zombi. Como apunta Julio César Scatolini,

la sociedad actual ha tomado el paradigma de la adolescencia, en donde el individuo pretende perpetuar la juventud, sin comprometerse sobre temas como el estado, el poder, la institucionalidad, predominando

\section{5 .}

Alusión a la novela de Martin Amis La zona de interés. Barcelona: Anagrama, 
la indiferencia y el relativismo, con el culto al cuerpo, redefiniendo el significado de la autonomía como derecho al ejercicio de la libertad personal, desde lo privado y sin importarle el ámbito social (indiferencia de masa). Se pretende vivir el aquí y el ahora, sin importar el futuro. De alguna manera esa adolescencia miedosa posmoderna nos plantea el no compromiso con el otro, la soledad, en definitiva, sentirnos vacíos. Las conciencias de los individuos son manipuladas por una cultura impuesta por los medios de comunicación, que inhibe el ejercicio de la razón y el pensamiento crítico (Scatolini 343-344).

En la trayectoria de esta cita, perpetuando un estado de juventud y de no compromiso, al sujeto Yammara no le preocupa hallarse a sí mismo o reconocerse a través del otro (o de lo otro). Su vacío se amarra a uno mayúsculo, el del enigmático Laverde, uno espejea al otro, en una operación de solapamiento de las huerfanías de ambos: Laverde arrastrando su soledad desde que salió de la cárcel, aislamiento que le costó su relación de pareja y el contacto con su hija Maya, y viviendo un presente en el cual se siente aplastado; y Yammara también preso de la apatía, desterrado al sofá de su departamento, en un monólogo entre el hoy que no comprende ni al que se integra y el futuro incierto.

Así se percibe un engranaje contrastante con el capítulo "La ilusión de impermanencia" de La identidad cosmopolita de Norbert Bilbeny, para quien "el cosmopolitismo se entiende como actitud personal, y por eso requiere dos hechos básicos en el individuo: quererlo e imaginarlo. Es decir, presupone una convicción moral, su elemento clave, y una disposición estética que apoye y estimule lo primero" (87). En la naturaleza personal del hombre cosmopolita se sobreponen dialógicamente la permanencia y la pertenencia, y si la primera resulta negada en tanto experiencia, el sujeto debe imaginarla, "No importa pertenecer, lo importante es no permanecer" (85).

No se trata de pensar al sujeto en una cuadrícula cerrada desde donde se instituya un espaciado físico determinado o la obligación de pertenecer a algo. La condición cosmopolita traza un desasosiego interior, una no permanencia, en definitiva, una huerfanía. Encerrado en una ciudad que apenas se despereza de una violencia incrustada como un elemento más de su topografía, Yammara está aprisionado sin lugar para los sueños: "La vida, en esas épocas que ahora me parecen pertenecer a otro, estaba llena de posibilidades. También las posibilidades, constaté después, pertenecían a otro: se fueron extinguiendo [...], hasta dejarme con lo que ahora soy" (Vásquez, El ruido 17). Desde esta óptica se valida la deriva del sujeto en 
permanente abatimiento y exhibiendo una morosidad decadente, "una vida que se le escurre a uno entre los dedos" (22).

Otra vez se regresa a Chambers y al individuo postmoderno cansado de un sentimiento profundo hacia el mundo exterior. La idea burguesa del hombre acomodado en el entorno familiar y con perspectivas a futuro, se diluyó en una imagen refractaria de soledad y decaimiento frente a los sentimientos que podían atarlo y ahora se ha vuelto "líquido". Como se especificó anteriormente, hay mucho de dejarse llevar por la circunstancia en la tipología del sujeto cosmopolita, en este caso Yammara, y salvo algunas excepciones, no se puede olvidar que él ha abandonado su profunda carga de compromisos políticos e ideales utópicos.

La creciente disipación del estilo personal (Fredic Jameson) hunde al sujeto en un estado de sopor, nada novedoso lo atrae, no se presencia "un yo que siente. Esto no significa que [...] carezca totalmente de sentimientos, sino que ahora tales sentimientos [...] son impersonales" (Jameson 36) y para él su condición se asocia con "la somnolencia general que flotaba en el mundo" (Vásquez, El ruido 96). A partir de Jameson es posible organizar varios cuadros en los que el sujeto Yammara funcionaría: exiliado por deseo en su departamento, sobre el sofá de la sala, control remoto en mano, pasa de un canal televisivo a otro arropado por imágenes de catástrofes, moda, reality show, hecatombes económicas, la dieta de horrores baudeleriana (Diarios Íntimos) que para él da igual; o sin preocupaciones, solo, "me iba a la sala, me sentaba en la silla reclinable y me quedaba así, mirando los movimientos de la noche en los cerros bogotanos, las luces verdes y rojas de los aviones que se veían cuando el cielo estaba limpio, el rocío que se iba acumulando en la ventanas como una sombra blanca cuando en las madrugadas caía la temperatura" (Vásquez, El ruido 58-59). Su vida corre como una película en cámara lenta: toca a tientas las paredes de un mundo reducido a la monotonía y sin "horizonte posible" (16).

Solo la violencia pasada triza por unos instantes esta dinámica del vacío a la que luego retorna porque solo en su interior se siente a gusto. Laverde, el jugador de billar, el desconocido, se cruza en el punto donde Yammara se ha detenido y le explota por un momento su conveniente laxitud, lo provoca a que salga a buscar alguna certeza: dentro de su historia como narcotraficante: "Yo soy el que sabe dónde se puede aterrizar, dónde se puede despegar. Yo soy el que sabe cómo se carga uno de estos aviones, cuánto soporta, cómo se distribuye la carga" (Vásquez, El ruido 186); en el relato que le exige la hija olvidada: "Quiero que me hable de mi padre [...] yo no llegué a... Yo era muy 
pequeña cuando él...” (106) y en los vestigios de la Hacienda Nápoles, la cual semeja una cicatriz que no cierra: "¿Y ha vuelto desde esa época? Porque yo no, no he vuelto nunca. El sitio está que se cae a pedazos, por lo que sé. Pero podemos ir de todas formas, ver qué hay, ver de qué nos acordamos. ¿Le suena la idea?'” (225). Pero en el exterior percibe su invalidez y aunque por segundos cae en la trampa de un cambio cuando "Maya Fritts volvió a mi lado y me puso una mano en la pierna y recostó su cabeza en mi hombro [...]. `Tengo que irme', le dije entonces" (253), la sensación se evapora y él retorna a su ciclo monótono donde retumba, como caja de resonancia, una frase que totaliza la huerfanía: "el mundo es un lugar demasiado riesgoso para andar por ahí" (259).

La huerfanía se adhiere a Yammara como su segunda piel, tanto que el final se reduce a la pérdida absoluta: cuando comprende que la esposa y la hija funcionan como anclas frente a su apático deambular, "la voz de Aura y la voz de Leticia, que habían llenado mis últimos años, que en más de un sentido me habían rescatado" (Vásquez, El ruido 255-256), es tarde, lo han dejado y ante esta carencia doblemente significada, perdido en su individualidad y en el abandono familiar, sólo tiene dudas: “¿Le preguntaría....? [...] ¿Guardaría silencio...? [...] ¿O trataría de convencerla?” (259). Como si con un borrador de preguntas (en el fondo de incertezas) se quitaran de golpe el presente y el atisbo de un futuro.

Con Yammara se percibe a un sujeto huérfano y presa del desánimo, descreído de cualquier utopía, a imagen del tiempo entrópico de la contemporaneidad, y frente al cual el lector únicamente puede acompañarlo si se dispone a sucumbir en su extraña dejadez, si echa a un lado los paraísos artificiales de la ilusión (Baudrillard, La transparencia del mal. Ensayo sobre los fenómenos extremos), es decir, de las promesas de mejores tiempos por venir. Con este sujeto no hay de dónde afincarse pues no hay salvación posible.

\section{MALLARINO: UN SUJETO CON UN AGUIJÓN DE MIEL}

Dentro de los elementos constitutivos de la huerfanía cabe reflexionar si existe un límite para el tedio o si no será éste un proceso de rumia y de construcción constante. Desde estas dudas se puede observar al sujeto Javier Mallarino, tan correcto y tan respetable pero sobre todo tan cansado. Como sujeto atraviesa dos momentos: en el primero, Vásquez lo arma como un individuo con poder, con un matrimonio estable (luego se divorcia y 
continúa una relación de amistad con Magdalena, su exmujer), una hija y amigos influyentes y con un reconocimiento público rozando el divismo; y en el segundo, como un individuo escéptico, huérfano de asideros, que se interroga una y otra vez sobre su vida, sus actos y sobre la huella definitiva de sus pasos en la opinión pública. Estos dos estadios se acoplan y también se contraponen pretendiendo prevalecer el uno sobre el otro; como observa Bauman: "La identidad, digámoslo claramente, es un 'concepto calurosamente contestado'. Donde quiera que usted oiga dicha palabra, puede estar seguro que hay una batalla en marcha" (Identidad 163).

A diferencia del desganado Yammara para quien el único momento al lado de Maya lo sacude, mas no lo suficiente para atarlo y por el contrario lo regresa a su zona de confort, Mallarino arrasa con su imagen y con lo que ha significado "ser él", en un final épico que semeja una hecatombe, pero la hecatombe del limite del hastio:

El presente era un peso y un estorbo, como la adicción a una droga. [...]. Buscará en la cocina una bolsa de basura, negra y con cinta naranja, y a manotazos empezará a meter en ella los frascos de tinta, las cuchillas, el bote de lápices [...] y con él los carboncillos, siete tipos distintos de minas, una espátula sin usar y un conjunto de plumas y pinceles, [...], y todo irá a parar al fondo de la bolsa. Uno por uno, Mallarino sacará los cajones de su archivador y los vaciará en la bolsa, y le gustará el sonido del papel cayendo en cascadas al fondo, la estática producida por el roce con el plástico. Arrancará al libertador enjuto y al papa ojeroso, al presidente recién elegido y al guerrillero recién muerto, y los meterá en la bolsa. Dará dos pasos atrás, mirará los espacios vacíos que van quedando por donde pasa su mano, claros abriéndose en medio de la selva espesa. Bajará de la pared la leyenda del aguijón y la miel y la meterá en la bolsa. Bajará la caricatura de Daumier y la meterá en la bolsa.

Y luego hará lo mismo con todo lo demás (Vásquez, Las reputaciones 138-139).

Esta bolsa de basura que por su contenido pesará tanto como el "saco de harina o de carbón, o la mochila de un soldado romano de infantería” (25) del poema "Cada cual con su quimera" de Baudelaire, culmina un periodo de agotamiento del sujeto porque, resulta útil recalcarlo, la huerfanía es un proceso que satura a Mallarino y lo obliga a enfrentarse consigo mismo y a pretender alejarse de su pasado hostil y su presente de éxito, validado éste precisamente por ese pretérito que ahora juzga erróneo: “¿De qué sirve? ¿De 
qué servía arruinar la vida de un hombre, aunque el hombre mereciera la ruina? ¿De qué servía ese poder si nada más cambiaba, salvo la ruina de ese hombre?" (Vásquez, Las reputaciones 136). Vuelta de tuerca a Baudelaire: Mallarino carga un peso muerto pero su quimera es él mismo, con sus actos y sus contradicciones.

A partir de la cita se afirma que manteniendo el tedio característico del sujeto contemporáneo, Mallarino revierte su actuación y esto tiene que ver con su pertenencia a una generación que no se derivó de la apatía frente a la política y los procesos sociales como la de Yammara, sino que la moldeó con sus juicios y se involucró con períodos históricos decisivos para Colombia, como el asesinato de Luis Carlos Galán o la etapa de terror impuesta por los carteles de la droga. Como revela en un momento, "asociaría cada suceso importante de su vida a la caricatura que estuviera haciendo en el momento (los pómulos sin ojos del guerrillero Trófico, secuestrador del cónsul holandés)" (Vásquez, Las reputaciones 30 ). Nunca estará al margen sino en la vorágine del suceso, influyendo con su trabajo, con la caricatura, su "aguijón de miel".

Metafóricamente, Yammara recibe el legado de Mallarino y solo se encoje de hombros porque no le interesa, no se siente representado. A través de Mallarino y Yammara se instala la constitución enfrentada de dos sujetos que confluyen en la construcción de subjetividades disímiles pero ambas desencantadas y huérfanas.

El proceso interior en Mallarino brota del desgaste y desde ahí va forjándose. Precisamente la portada de la novela lo define: una imagen de Michael Shumate titulada "Man with open trench coat with faces inside". El elemento gráfico complementa la sustancia cambiante y efímera del sujeto. Un adulto viste una larga gabardina y en su interior aparecen seis rostros con expresiones diferentes, como si fueran atuendos que pudieran escogerse de acuerdo con la ocasión; rostros como corbatas, inequívocos de la transitoriedad emocional. La mano derecha parece decidirse por el primer semblante y detallando que el hombre no posee una cara delineada se sobreentiende que lo colocará sobre el vacío de su rostro. La descripción de la foto en internet está acompañada de palabras a manera de descriptores: cara humana, persuasión, máscara, deshonestidad, identidad-persona, irreconocible. La desrostrificación como signo de maleabilidad identitaria, tal y como acotaron Deleuze y Guattari: "Sólo en el seno del rostro, del fondo de su agujero negro y sobre su pared blanca, podremos liberar los rasgos de rostridad como pájaros" (193). Rostridad que se asocia con la falta de solidez constitutiva del sujeto, con las llamadas por Bauman "identidades fluidas" (Miedo líquido). Precisamente se trata de ver 
a Mallarino a través de estas caras creadas por Shumate, las cuales pueden recomponerse sobre el talante principal.

Estas faces mutantes desordenan cualquier intento de coherencia. ¿No podría pensarse que en lo profundo de esta transmutación se aloja la huerfanía? Mallarino encaja con un talante dulce y sereno que todavía extraña a Magdalena, su cuerpo con "las sombras y las estrías no eran sombras y estrías, sino mensajeros de todo lo que había sucedido en su ausencia: todo lo que Mallarino se había perdido" (Vásquez, Las reputaciones 45); con otro orgulloso que acepta los honores por una profesión exitosa, "el orgasmo correspondiente a un largo coito de cuarenta años con su oficio" (16); con uno de facciones justas, que se aferra al pasado y al gesto de condenar a un "villano", a ese Cuéllar del que poco se sabe (o se sabe lo justo), un "tipo repugnante" (72) a quien "he humillado, [...], lo he ridiculizado, y [...] me viene a lamer el culo" (72); con una cuarta cara que contradice la anterior y que refleja una mueca parecida a "Ya no había nada que lo uniera a [ese] pasado" (137) y que lo convierte en "un calumniador o simplemente irresponsable, $[\ldots]$ destructor de la vida de un hombre o simplemente abusador impune del poder mediático" (135); y hasta con una quinta, esperanzada por la reconciliación con la hija alejada, en falta, "siempre estaba de viaje, [...], no se detenía nunca" (124).

Múltiples caras y un solo Mallarino encerrado en la contradicción o varios Mallarinos idénticos al individuo de la portada del libro que no poseen un único rostro y seleccionan el perfil más pertinente según la circunstancia, aquel que pueda defenderlos de sus carencias presentes. Como si contaran con la posibilidad de hacer malabares con su pluralidad y, parafraseando a Bauman (Identidad), lograran transformarse en un abrir y cerrar de ojos en los personajes que quieren ser, que quieren que otros vean y que quieren que reconozcan.

Se retoma a Mallarino en un instante de la novela, antes del homenaje, mientras camina por una desconocida Bogotá que le borra sus coordenadas y lo empuja hacia la añoranza, huérfano de creencias, en "Un errar sin destino fijo en el que se notan las marcas del spleen del flâneur baudeleriano" (Aínsa 120). Desde el banco donde lustra sus zapatos, cual atalaya moderna, encuadra los retazos de quien es (más bien de quien pretende ser) y siente la carencia adonde asirse:

buenas maneras: especies en vías de extinción en esta Bogotá inelegante y malencarada y tosca, la Apenas sudamericana. ¿Quién había dicho aquello de que en Bogotá hasta los emboladores citaban a Proust? 
Un inglés, se dijo Mallarino, sólo un inglés es capaz de perpetrar declaraciones semejantes. Claro, lo había dicho tiempo atrás: lo había dicho en otra ciudad, la ciudad desaparecida, la ciudad fantasma, [...], la ciudad de La Gran Vía, cuya puerta de entrada Mallarino hubiera podido ver, unas décadas atrás, desde el lugar de la acera donde ahora se detenía distraídamente, a un paso corto de la calzada hostil, la mirada perdida entre las busetas de ventanas iluminadas. [...]. Muchas tiendas y muchos cafés habían desaparecido, La Gran Vía entre ellos (Vásquez, Las reputaciones 20-21).

En la cita se enfatiza la condición de ajenidad como rasgo esencial de una ciudad que descuadra los ejes para organizarla y "donde se cruzaban, ignorándose, miles de itinerarios individuales" (10), como argumentó Marc Augé con respecto a las megalópolis. Mallarino se encuentra solo, flota entre recuerdos, algunos, inclusive, juegan con él como la figura del caricaturista Rendón, muerto hacía 79 años, que atraviesa espectralmente el paisaje de su mirada y queda como una interrogante, quizá como "uno de esos recuerdos falsos que todos tenemos" (Vásquez, Las reputaciones 21), pero esto apunta hacia la ruptura entre el habitar del afuera y el habitar del adentro, hacia el engranaje roto sin posibilidad de colocarlo nuevamente en la maquinaria del ser:

Sí, la ciudad era otra. Pero no era nostalgia lo que embargaba a Mallarino al constatar los cambios, sino un curioso afán por detener la marcha del caos, como si haciéndolo fuera a detener también su propia entropía interior, la lenta oxidación de sus órganos, la erosión de su memoria reflejada en la memoria erosionada de la ciudad (Vásquez, Las reputaciones 15).

“[S] u propia entropía interior": a través de la huerfanía, el escindido Mallarino se elabora entre el pasado de la urbe, cuando todavía podía testimoniar quién era, y el presente que lo expulsa hacia un estado anímico de desolación y que más tarde lo condenará a exiliarse hasta de su profesión.

La erosión de este sujeto tiene que ver con la muerte de las certezas y también con irse deshabitando, dejándose caer como la tierra que se desprende de una piedra: "la cara cansada, cerró los ojos con fuerza, los volvió a abrir" (Vásquez, Las reputaciones 20 ). 


\section{VÁSQUEZ Y CARBALLO: DOS SUJETOS EN LA HUERFANÍA DE LA RUINA}

La forma de las ruinas ${ }^{7}$ problematiza una huerfanía diferente a la de las novelas precedentes: la del sujeto frente a la historia. Buscando establecer un diálogo entre los tres relatos se pretende pensar la huerfanía a partir de una premisa vinculada con la relación de los sujetos Vásquez y Carballo con una historia agujereada por la intriga, a la sombra de la cronología oficial, que cuesta armar como creíble y que les otorga la condición de huérfanos en sus presentes.

El sujeto autobiográfico Vásquez ${ }^{8}$ confiesa: "yo vivía en un mundo [...] irónico y escéptico, un mundo regido por el azar, el caos, los accidentes y las coincidencias. Y lo que me pedía Carlos Carballo era salir durante un instante y vivir en otro mundo, y luego volver al mío para contar lo que había visto" (Vásquez, La forma 538). El autor se coloca como sujeto receptor de las narraciones de otros sujetos involucrados en las investigaciones de dos hechos definitorios para Colombia: por una parte, Carlos Carballo, defensor de la teoría conspirativa sobre el asesinato de Jorge Eliécer Gaitán en 1948, acto que provocó "El Bogotazo"; y por otra, Marco Tulio Anzola, abogado pesquisador en el crimen del general Rafael Uribe Uribe ocurrido 34 años antes. Del último, Vásquez lee sus apuntes, una suerte de bitácora histórica que guarda celosamente el primero; con Carballo conversa, discute y mantiene un vínculo que se forja entre la dependencia y el odio. Tanto leyendo como hablando el sujeto Vásquez es un huérfano incrédulo pues su aproximación

7 Como relato padece de demasiadas digresiones, de ahí que la investigadora lo considere menos logrado que las otras dos novelas analizadas. Además, la inclusión de fotografías no aporta al despliegue narrativo, sobre todo en la parte del asesinato de Kennedy.

Si ciertamente se produce una sutura biográfica entre el autor Vásquez y el sujeto Vásquez en esta novela, se coloca cierta tensión en este solapamiento para no realizar una lectura lineal, poco fructífera, que no permita encontrar entresijos entre la categoría ficcional (la del sujeto) y la autoral, como apuntó Bajtín en Estética de la creación verbal: "Es imposible que uno viva sabiéndose concluido a sí mismo y al acontecimiento; para vivir, es necesario ser inconcluso, abierto a sus posibilidades [...]; valorativamente, hay que ir delante de sí mismo y no coincidir totalmente con aquello de lo que dispone uno realmente" (20). En esta dirección se producen rupturas entre el sujeto ficcional y el biográfico, como revela el propio Vásquez al finalizar la novela, en su Nota del autor: "La forma de las ruinas es una obra de ficción. Los personajes, incidentes, documentos y episodios de la realidad, presente o pasada, se usan aquí de forma novelada y con las libertades propias de la imaginación literaria” (549). 
a la historia no tiene que ver con el fragmento que se pierde entre los relatos oficiales, de ahí que le grite a Carballo: "No son evidencias, no son nada de eso. Son simplemente restos, ruinas humanas" (540).

Efectivamente, la novela se va edificando sobre la ruina, no cualquiera sino la de la historia colombiana9 ${ }^{9}$ una radiografía, una vértebra o una bala retorcida, con lo cual se podría inferir un sujeto interesado en un acontecimiento como el del asesinato del líder Gaitán y los restos del evento que permanecen. Pero es una trampa. Ante cada interrogante de Carballo se percibe el desapego del sujeto Vásquez, quien "nunca h[a] sentido la devoción incondicional que otros sienten por la figura de Gaitán, que me parece más quejumbrosa de lo que se admite" (Vásquez, La forma 25) y quien cuestiona la posibilidad de la conspiración que puso término a las aspiraciones presidenciales del candidato liberal. Alejado de la trama de su país, pues cree que ya cumplió una deuda cuando escribió sobre el pasado de la violencia en El ruido de las cosas al caer, "Fue un año y medio que pasé recordando esos días sin parar, un año y medio pensando en estos muertos, [...] [y] en nosotros, los vivos, que seguimos tratando de entender lo que ocurrió" (188), piensa una y otra vez en que los relatos al margen de la palabra oficial constituyen "fábulas de niños, [...], un lugar virtual al que vamos para hacer turismo, revivir nostalgias o tratar de encontrar algo que se nos ha perdido" (26).

Se está frente a un sujeto escéptico como Yammara, que no cree en conspiraciones pues éstas pueden erosionar su conocimiento y sus certezas. Expandiendo esta posibilidad, tampoco siente empatía por descubrir posibles pliegues dentro de su historia nacional (pliegues entendidos como "acontecimientos singulares incluidos en la mónada como predicados primitivos", según Deleuze en El pliegue: Leibniz y el barroco 112); este sujeto se encuentra inapetente frente a la apertura de esa otra Historia que vuelve locos a Anzola y a Carballo, como si se encerrara en un cuarto "sin puerta ni ventana" (Deleuze) y no hiciera ni el más mínimo gesto por abandonarlo; a contracorriente de lo que plantea el autor de Diferencia y repetición, "no necesita un pequeño agujero, una pequeña apertura" (112) para rebasar su postura cómoda y segura.

9 Desde la página 92 hasta la 101 se desmenuza el asesinato de John Fitzgerald Kennedy como un preámbulo a las dos conspiraciones que interesan: la de Uribe Uribe y la de Gaitán. Vásquez incluye un recorte de prensa y los seis fotogramas famosos de la película de Abraham Zapruder. 
Más allá de un final empujado por una premura poco clara -se realiza un trueque: Carballo devolverá la vértebra de Gaitán que hurtó de casa de Benavides, personaje gozne entre ambos sujetos, y a cambio Vásquez escribirá la microhistoria proporcionada por el primero- el último puede mirarse como alguien huérfano de arraigos históricos y esto lo potencia a la deriva del pasado y sin mayores complicaciones para prever el futuro en tanto "lugar demasiado riesgoso para estar por ahí" (259), frase de El ruido de las cosas al caer que permite un diálogo con La forma de las ruinas: "fui al cuarto de mis hijas, que también dormían, y cerré la puerta y me senté en su silla verde adornada de pájaros y me quedé así, en la oscuridad de la habitación pacífica, viendo con envidia el sosiego de sus cuerpos largos" (Vásquez, La forma 547).

Este sujeto pasa por desechar los posibles problemas de una investigación histórica; no es que la pereza lo invada, sencillamente no desea complicarse y nunca ha tenido "interés irracional por los objetos del pasado, esos fantasmas silenciosos" (Vásquez, La forma 49). Siempre repite el mismo círculo: la familia queda como reducto, el consuelo ante el espantoso mundo, y huye frente a cualquier eventualidad que pueda descolocar sus coordenadas preestablecidas. Ya se había adelantado: él zanjó su deuda con la historia de Colombia: "Y juro que pensé, tras terminar El ruido de las cosas al caer, que así quedaban saldadas mis cuentas personales con la violencia que me había tocado vivir" (188) y reconoce que "vivía en un mundo [...] irónico y escéptico, un mundo regido por el azar, el caos, los accidentes y las coincidencias" (538).

Resulta pertinente pensar a través de Deleuze en la necesidad de que esta novela posea lo que él denomina "un cuerpo con exigencia", es decir, un cuerpo-nación constituido por ruinas, vestigios y sospechas, con lo cual se produciría una vuelta de tuerca a la denominada "nueva novela histórica" 10 encargada de enfatizar "los personajes públicos que ofrecen una veta diegética más rica a la mirada ficcional" (36), como acota Carlos Pacheco

10 Aunque no resulta objetivo de este artículo se apunta que el concepto sobre la nueva novela histórica ha sido trabajado recurrentemente por la crítica desde mediados del siglo $\mathrm{XX}$, entre otros autores fundamentales por el venezolano Carlos Pacheco, quien lo abordó con profundidad en los textos "Reinventar el pasado: la ficción como historia alternativa de América Latina" (1996), La patria y el parricidio: estudios y ensayos críticos sobre la literatura y la escritura en la narrativa venezolana (2001) y Nación y literatura: itinerarios de la palabra escrita en la literatura venezolana (2006, en colaboración con Luis Barrera Linares y Beatriz González Stephan). 
en "Reinventar el pasado: la ficción como historia alternativa de América Latina", sino que el autor decide no centrarse en "personajes públicos" con algo que decir o demostrar, sino en sujetos anodinos y obsesionados por el pasatiempo de hurgar en la intimidad o en la oscuridad de otros seres, éstos sí históricamente célebres.

El libro de Vásquez no se acomoda alrededor de la vida de hombres probos, asesinados por conjuras del poder de turno, sino que se mueve en la órbita de "investigadores" improvisados que habitan en apartamentos de segunda mano, sin recursos económicos para llevar adelante sus proyectos, como Carballo, o que están comenzando una carrera prometedora pero se precipitan en la locura y son expulsados hacia la anulación absoluta, el caso de Anzola. Son los sujetos de la huerfanía en una historia que no les perteneció desde el momento cuando comenzaron a leerla desde sus entresijos. La ruina y la pérdida identifican tanto la historia que rastrean sobre Colombia como sus identidades.

Se empalma entonces con el concepto de ciencia menor de Deleuze y Guattari en la dirección de identidades elaboradas a partir de un fluir constante de la historia, ésta con la suficiente fuerza subterránea para erosionar hasta formar agujeros y conjeturas que quiebran supuestas verdades hasta aposentarse. En Mil mesetas. Capitalismo y esquizofrenia, estos teóricos apuntan hacia la creación de un modelo que potencia la "heterogeneidad, [y] que se opone al modelo estable, eterno, idéntico, constante. [...] el atomismo [...] [que] proporciona ese modelo de heterogeneidad" (368). Desde aquí la propuesta de La forma de las ruinas adquiere peso ya que se trata de poner en escena una historia armada con las esquirlas de acontecimientos aparentemente resueltos que conducen a desarmarla y a elaborar sujetos escindidos, en contradicción y huérfanos de evidencias y certidumbres, defensores de aquella historia que "puede ser, [...], un poquito mentirosa. [...] distinta de la que nos han vendido los manuales escolares" (Vásquez, La forma 248), "un relato construido sobre otro relato, un artificio de verbos y sustantivos" (250).

Esto lleva directamente al sujeto Carballo, la tipología más contradictoria y reveladora de la novela, empeñado en levantar una "historia colectiva de la infamia" a través del forjamiento de un vínculo entre los asesinatos de Uribe Uribe y Gaitán y el cual se produce mediante una lectura a los vestigios de ambos hechos, lo que Vásquez denomina "la memoria de los huesos" (Vásquez, La forma 541).

El sujeto precisa de una voz, la de Vásquez, que relate la investigación que ha acumulado durante años, sin ésta no se justifica. Sin embargo, tal necesidad 
de producir un relato sobre una zona particular de eventos violentos de la historia colombiana es para él un arma de doble filo: se convierte en un ser enajenado, huérfano de lazos con el presente, motivo de burla (hasta para el propio Vásquez), detenido por la policía cuando intentaba robar del museo el traje que vestía Gaitán el día de su asesinato, esto último condicionante de arrastre para su futuro. Con su palabra devenida obsesionante pesquisa, al margen de la versión oficial, legitima otro modo de situarse con respecto al ser nacional y al reconocimiento como parte de una comunidad histórica.

Parafraseando lo que el sujeto ficcional Vásquez cuenta como experiencia cuando terminó su novela El ruido de las cosas al caer, Carballo ha recibido las desmesuras, los errores y los crímenes del pasado en un tiempo presente que hereda un inventario sin posibilidades de escogencia. De ahí la duplicidad, el elemento esquizoide y la imposibilidad de hilvanar una investigación pausada. Todo en él es apresurado y violento, un individuo bajo la intemperie y la sospecha del presente: "'Las coincidencias no existen'. Abría los ojos cuando decía esto: que las coincidencias no existen. Yo nunca he visto a alguien que abra tanto los ojos, que levante tanto las cejas" (Vásquez, La forma 112).

Carballo es la subjetividad más completa de ciudadano de la huerfanía en la narrativa de Vásquez. El pasado lo expulsa hacia una búsqueda veleidosa y torturante, “¿Cómo hago yo para salirme de este mundo mío donde todos estamos locos? [...]. 'Yo sé muy bien lo que quiere decir. Ya me lo dijo antes: que soy un ocioso'" (Vásquez, La forma 61-62) y el ahora lo encierra para el futuro: "estaba subiendo laboriosamente a una furgoneta policial, las manos esposadas detrás de la espalda y la cabeza hundida entre los hombros" (13). Como Mallarino también sobrelleva una quimera baudeleriana, solo que más pesada porque en el saco carga la historia fracturada de una nación.

A diferencia de lo que sucede en El ruido de las cosas al caer y Las reputaciones, ambas novelas con un sujeto claramente definido por la huerfanía, en La forma de las ruinas ésta se reparte entre dos sujetos con diferentes motivaciones y en contextos que se superponen los unos con los otros: Carballo y sus obsesiones por los crímenes pasados de Uribe y de Gaitán, y Vásquez arrastrado hacia historias que no le interesan pero que se cruzan. El contacto con el pasado deja un presente de profunda soledad, aquella que hace que se cuestionen íntimamente y que perciban que se encuentran a la intemperie de cualquier certeza. Ambos sujetos comparten interrogantes sobre el ayer que no les permite explicarse el tiempo actual, al contrario, sobreviven en una absoluta carencia de certidumbre, de ahí que se manejen con la ruina como madero de donde asirse en el naufragio cotidiano de sus vidas. 
A modo de cierre, la huerfanía de los sujetos está en función de un "uso de motivos [históricos] [...] que aluden a la orfandad, el desamparo" (S/A 1), cita sobre Quezada tomada anteriormente, pero sobre todo pasa por una representación del resto como una bisagra entre el pasado y el presente que solo deja preguntas por doquier. Una vértebra de Gaitán, un pedazo de hueso de Uribe, "ruinas humanas, sí, las ruinas humanas de unos hombres nobles" (Vásquez, La forma 540) quedan tanto como el vestigio del ayer como de un presente que se mantiene circulando a partir de la incompletud heredada. Desde aquí, ¿pudieran creer estos sujetos en alguna ilusión de futuro?

\section{CONCLUSIVO: LA FORMA DE LA HUERFANÍA}

Las novelas El ruido de las cosas al caer, Las reputaciones y La forma de las ruinas rompen con la representación de temáticas que parecían monolíticas en la narrativa colombiana más reciente, entre éstas las que se centran en la violencia durante los tiempos turbulentos del narcotráfico, el paramilitarismo y la guerrilla, para concentrarse en una sociedad a la deriva (consecuencia del horror pasado, no se niega) a través de un sujeto que exhibe la condición de huerfanía, sin asideros y vacío.

Detrás de la catástrofe del avión donde viajaba Elena Fritts, la madre de Maya y esposa de Laverde, de la enorme bolsa de basura en la cual Mallarino echa sus herramientas de caricaturista, y del frasco con el fragmento de la columna vertebral de Gaitán, celosamente guardado, se asienta la propuesta del autor: la de una narrativa que trenza los paisajes físicos y emocionales de sus sujetos mediante el reconocimiento de su circunstancia de huerfanía.

Estos sujetos son como ruinas enquistadas, restos del presente y de cara al futuro, idénticos a los de la Hacienda Nápoles que recorren Yammara y Maya, a la casa de Gaitán convertida en museo y de donde Carballo intenta sustraer el traje manchado con la sangre del líder, y al centro irreconocible de Bogotá que con su vocería hace trastabillar a Mallarino. Sujetos en huerfanía, formas textuales que consigue Vásquez para explicar y explicarse la vida contemporánea y su ruido cada vez más monótono al caer. 


\section{BIBLIOGRAFÍA}

Aínsa, Fernando. "Nueva cartografía de la pertenencia. La pérdida del territorio en la narrativa latinoamericana”. Iberoamericana 54 (2014): 111-126.

Arfuch, Leonor. El espacio biográfico. Dilemas de la subjetividad contemporánea. Buenos Aires: Fondo de Cultura Económica de Argentina, 2002.

Augé, Marc. Los no lugares. Espacios del anonimato. Barcelona: Gedisa, 2008.

Bajtín, Mijaíl. Estética de la creación verbal. Buenos Aires: Siglo XXI Editores Argentina, 2005.

Baudelaire, Charles. Pequeños poemas en prosa. Barcelona: Edicomunicación, 1995.

Diarios Íntimos. Buenos Aires: Leviatán, 2006.

Baudrillard, Jean. La transparencia del mal. Ensayo sobre los fenómenos extremos. Barcelona: Anagrama, 1997.

El crimen perfecto. Barcelona: Anagrama, 2000.

El complot del arte. Ilusión y desilusión estéticas. Buenos Aires: Amorrortu/ editores, 2007.

Bauman, Zygmunt. Identidad. Argentina: Losada, 2005. 2010.

Miedo líquido. La sociedad contemporánea y sus temores. Madrid: Espasa Libros,

Benjamin, Walter. Poesía y Capitalismo. Iluminaciones II. Madrid: Taurus, 1972.

Bilbeny, Norbert. La identidad cosmopolita. Barcelona: Kairós, 2007.

Cánovas, Rodrigo. "Señas de identidad en el Chile actual: de blasones, orfandades y Cofradías". Literatura y Lingüística 30 (2014): 121-133.

Chambers, Iain. Migración, Cultura, Identidad. Buenos Aires: Amorrortu Editores, 1995.

Deleuze, Gilles. El pliegue: Leibniz y el barroco. Buenos Aires: Paidós, 2014.

Deleuze, Gilles y Félix Guattari. Mil mesetas. Capitalismo y esquizofrenia. Valencia: PreTextos, 1994.

Foucault, Michel. Tecnologías del yo y otros textos afines. Barcelona: Paidós, 1991.

La hermenéutica del sujeto: Curso en el Collège de France: 1981-1982. Buenos Aires: Fondo de Cultura Económica, 2014.

Güelman, Martín y Pablo Borda. "Narrativas y reflexividad: los efectos biográficos del enfoque biográfico". Revista Latinoamericana de Metodología de las Ciencias Sociales 4 (1), 2016.

Jameson, Fredric. Teoría de la postmodernidad. Madrid: Trotta, 1996.

Lechner, Norbert. "Un desencanto llamado posmoderno". DOCUMENTOS DE TRABAJO 369. Programa FLACSO-Santiago de Chile, (1988): 1-36.

Lyotard, Jean-François. La condición posmoderna. Informe sobre el saber. Madrid: Ediciones Cátedra, 1987.

“¿Qué es lo Posmoderno?”. Recuperado de: https://analisisdeldiscursoute.files. wordpress.com/2012/05/lyotard-jean-francois-que-es-lo-posmoderno.pdf. Revisado el 7 de septiembre de 2015 . 
Quezada, Jaime. Huerfanías. Santiago de Chile: Pehuén Poesía, 1985.

"Mi poética sobre Huerfanías". Revista Chilena de Literatura 38 (1991): 119-121.

Scatolini, Julio César. "El pasaje del hombre de la sociedad moderna a la posmoderna". ANALES 41 (2011): 338-346.

S/A. "Huerfanías (1985)". Recuperado de: http://www.memoriachilena.cl/602/w3-article-94812. html. Revisado en 2016.

Thiebaut, Carlos. Historia del nombrar. Dos episodios de la subjetividad. Madrid: Visor, 1990. "La construcción del Sujeto: entre la filosofía y la literatura". Figuras del logos. Entre la filosofía y la literatura. Comp. María Teresa López. México: Fondo de Cultura Económica, 1994. 186-204.

Vásquez, Juan Gabriel. El ruido de las cosas al caer. Bogotá: Alfaguara, 2011.

Las reputaciones. Bogotá: Alfaguara, 2013.

La forma de las ruinas. Bogotá: Alfaguara, 2015.

Vattimo, Gianni. El sujeto y la máscara. Nietzsche y el problema de la liberación. Barcelona: Península, 1989. 